\title{
A Review of SARS-CoV-2, Responsible for COVID-19: History, Biology, Infection Mechanism, Antigenic Vaccines, their Risks and How an Alternate RBD Vaccine is Safer? \\ ZMG Sarwar Jahangir and Arleta Helena Marnik \\ Department of Biological Sciences, Kingsborough Community College, The City University of New York, 2001 Oriental Boulevard, Brooklyn, NY 11235.
}

\section{$\underline{\text { Introduction }}$}

1. History of coronavirus human infection, mortality, and socioeconomic impacts:

Based on studies of RNA-dependent RNA polymerase molecular clocks, it was concluded that a common ancestor of avian coronavirus (CoV) appeared about 10,000 years ago and a mammalian CoV appeared about 7,000-8,000 years ago [1]. Like many other diseases, CoV spread from region to region over the last 5,000 years more frequently as human travel increased over the millennia [1]. The first human CoV, HCoV (human coronavirus)-229E, strain B814, was isolated from human upper respiratory tract infections (URTIs) in 1965 [2-4]; since then, many more strains of coronaviruses, such as HCoVNL63, HCoV-229E, HCoV-OC43 and HCoV-HKU1, have been identified causing human URTIs leading from mild to moderate common cold infections [5]. Some of strains known were more severe and even fatal for humans [4].

In November 2002, a coronavirus infection started an epidemic in Foshan Municipality in Guangdong Province, China, causing severe acute respiratory syndrome (SARS) [6]. It ultimately spread to other countries in North America, South America, Europe, and Asia infecting at least 8,098 people, out of whom 774 died $[4,6]$. The patients were diagnosed with flu-like symptoms which progressed into atypical pneumonia followed by increasing shortness of breath and oxygen desaturation [7]. This human disease was caused by the SARS-CoV virus which has an $88 \%$ to $95 \%$ homology to the coronavirus originating in horseshoe bats (Rhinolophus pussilius, R. macrotis, R. pearsoni, and R. sinicus) and a 99.6\% homology to the coronavirus found in masked palm civets, Paguma larvata [8-10].

The above incidents were followed by another outbreak of a SARS coronavirus infection known as Middle East Respiratory Syndrome (MERS), diagnosed in September 2012 in Saudi Arabia, which over time spread outward across 27 countries, ranging from West Africa to South Korea $[11,12]$. It was determined that the MERS coronavirus (MERS-CoV) originated in the Egyptian tomb bat, Taphozous perforates, was transmitted to the dromedary camel, Camelus dromedarius, and then passed to humans 
$[13,14]$. MERS-CoV infected 2,400 persons, causing over 850 deaths (35\%) in addition to diseases in the hearts, kidneys, and lower respiratory tracts in those who survived the infection $[11,15,16]$.

In November 2019, SARS emerged again in Wuhan, a city of 11 million people in Hubei Province in Central China, and ultimately caused a global pandemic [17]. Zhang Jixian was the first doctor who noticed uncommon abnormalities in the thorax CT scan images of lungs of an elderly couple and reported it to the head of the hospital on December 27, 2019, which was recorded by the hospital's officials and reported to the Chinese Center for Disease Control and Prevention and China's National Health Commission [18]. The causative coronavirus agents for the recent outbreaks in Guangdong, the Arabian Peninsula, and Wuhan are called SARS-CoV, MERS-CoV, and SARS-CoV-2, respectively, and their outbreaks are known to cause human mortality [19-21]. The genome sequencing of SARS-CoV-2, SARSCoV, and MERS-CoV has revealed the close resemblance of these viruses to each other, as reported by Naqvi and colleagues [22]. They also reported that the cytokine profiling and inflammatory signaling in response to a SARS-CoV-2 infection is different than in SARS-CoV and MERS-CoV infections. This was also revealed by the ineffectiveness of several medications in controlling SARS-CoV-2, which were effective against SARS-COV and MERS-CoV [22].

Due to the global spread of SARS-CoV-2 infections that had begun in Wuhan, China, the World Health Organization (WHO) of the UN announced on February 11, 2020, a common name, COVID-19, to refer to the disease [23]. SARS-CoV-2 has a wide range of host adaptability and is capable of causing diseases in humans, camels, pigs, mice, bats, pet dogs and cats, masked palm civets, and chickens [24]. The novel coronavirus SARS-CoV-2 that emerged in the fourth quarter of 2019 in Wuhan spread quickly around the world, and by March 19, 2021, the infection figures reached to 122,036,229 confirmed cases including 2,694,915 deaths [25]. The transmission of coronavirus outbreaks is shown in Figure 1, attached. 


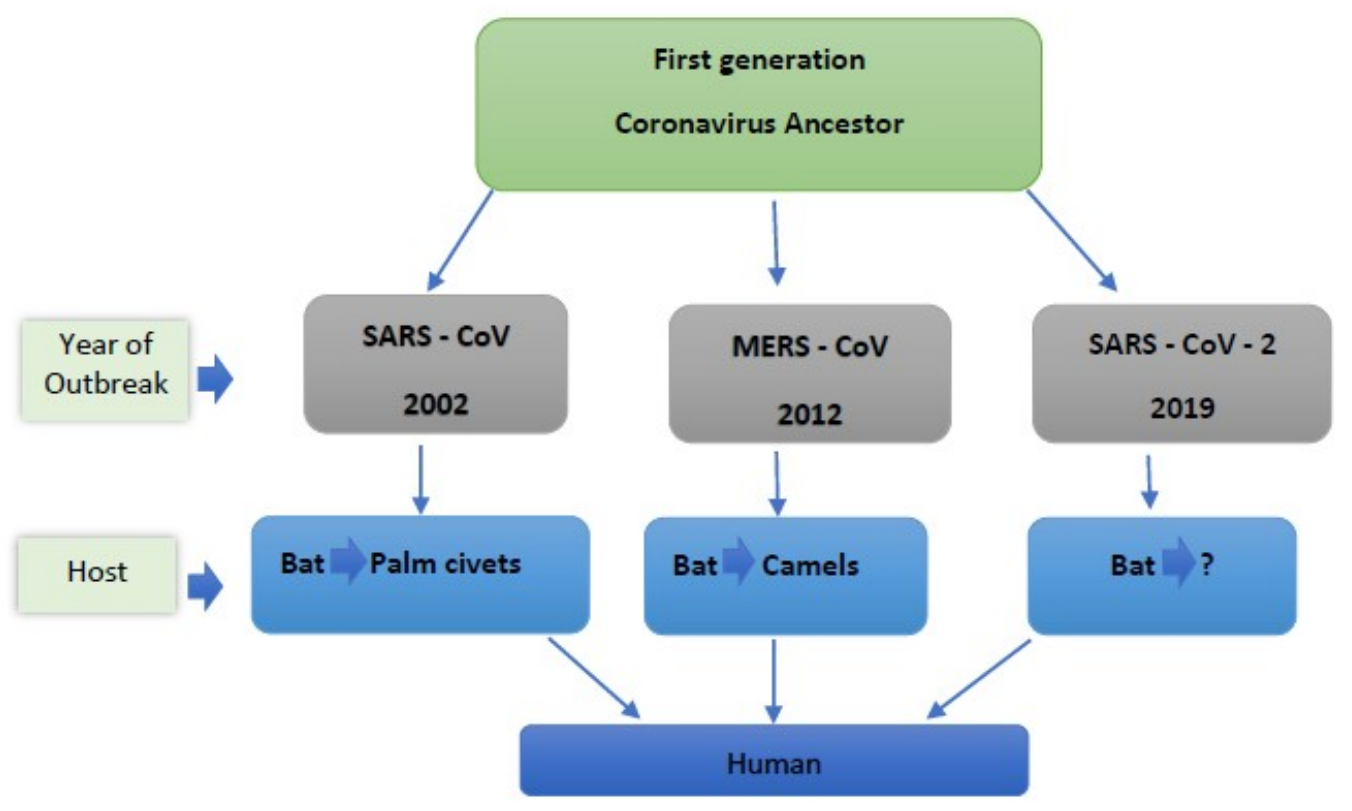

Figure 1. Transmission pattern of coronavirus outbreaks 2002 - 2019 [9,32]:

SARS-CoV (2002) Bat $\rightarrow$ Palm civets $\rightarrow$ Human; MERS-CoV (2012) Bat $\rightarrow$ Camels $\rightarrow$ Human; SARS-CoV-2 (2019) Bat $\rightarrow$ ? $\Rightarrow$ Human.

Statistically, this affected about $1.5 \%$ of the human population infected and also reduced global GDP, as of May 2020, by $\$ 5.8$ to $\$ 8.8$ trillion [26]. Lockdowns, increases in unemployment, remote schooling, and quarantine led a global crisis where millions of families fell into poverty and became isolated from their kith and kin [27]. Those experiencing excessive stress from stringent quarantine precautions suffered from an increase in plasma adrenal cortisol, resulting in sleep disorder, obesity, diabetes, and asthma [28]. Long-term exposure to hardship during maternity has the potential to cause delays in embryonic development due to an imbalance in the neuroendocrine immune system and damage of telomeres [29].

\section{Origins of human coronavirus:}

The genome of a coronavirus is composed of RNA molecules in the range of 26,000 to 32,000 nucleotide bases in length containing recombination of mammalian and avian coronavirus ancestors 
[30,31]. The SARS-CoV-2 is found to have $96.1 \%$ genetic homology to another coronavirus, SARSr-RaBatCoV-RaTG13, found in the horseshoe bat, Rhinolophus affinis [32,33].

The coronavirus spike (S) protein genome analysis supports a possible recombination of homologous coronavirus genomes found among bats and snakes [34]. The receptor binding domain (RBD) of the SARS-CoV-2 S-protein has $97 \%$ symmetry in amino acid residues to a pangolin (Manis javanica) coronavirus, SARSr-CoV-MP789 [32,33,35]. The above literature suggests a natural recombination of RBD domains of the S-protein between horseshoe bat and pangolin coronaviruses. In general, diversity of viruses results from point mutations, genomic template-switches in replication, and genetic recombination [30,31]. In addition, several scientists experimentally confirmed that SARS-CoV-2 can bind to receptor ACE-2 found in human, Chinese horseshoe bat, civet, and pig cells, supporting the idea that the SARS-CoV-2 RBD can mediate infection in humans and in other mammals too [36].

In a separate report, [37] described, taxonomically SARS-CoV-2 is closely related to SARS-CoV and SARS-related bat and pangolin coronaviruses that share a common receptor, ACE-2, binding. By amino acid analysis, they found that the SARS-CoV-2 S1 spike protein domain is closely related to the SARS-CoV and SARS-CoV-2 viruses, while the S2 domain is closer to MERS-COV and HCoV-OC43 [37,38]. Both S1 and S2 domains are the key components in the evolution of the structural loop affecting the virus's stability and transmission [37].

\section{Description of SARS-CoV-2:}

SARS-CoV-2 is a positive single stranded RNA virus and belongs to the genus Betacoronavirus [39]. Many SARS-CoV-2 RNA genome sequencing studies have found some variations in the lengths of the SARS-CoV-2 genomes, ranging from approximately 29,000-32,000 nucleotides. In a study of fulllength SARS-CoV-2, the maximum length was determined to be 29,742 nucleotides, while the full lengths of the Wuhan strain SARS-CoV-2 were reported to vary between 29,881-29,903 nucleotides in length with 10-14 open reading frames (ORFs) encoding 9,860 amino acid residues [40-44].

The SARS-CoV-2 mRNA is housed in a spherical body that is $60-140 \mathrm{~nm}$ in diameter and is encapsulated by a bilayer phospholipid membrane containing envelope (E), membrane (M) and spike (S) proteins $[40,45,46]$. The $E$ and $M$ proteins are composed of 76-109 amino acids while the spike protein is 1273 amino acids in length $[40,45,46]$. The number of proteins per SARS-CoV-2 virion varies as follows: E proteins, 100-200; M proteins, approximately 1100; nucleocapsid (N) proteins, 730-2200, and approximately $90 \mathrm{~S}$ proteins $[40,45,46]$. The rate of evolution for SARS-CoV-2 is $0.27-2.38$ substitutions $\times$ 
$10^{-3}$ per site per year; mutation is $3.5 \times 10^{-6}$ per infection; infection time is $10-15$ minutes; and progeny takes 7-8 hours and yields 6 to $7 \times 10^{2} \mathrm{pfu}$ per burst [40]. In addition, there are several non-structural proteins, which were found to which play critical roles in SARS-CoV replication and transcription [47].

4. Infection mechanism:

It is well known that SARS-CoV-2 infects humans by attaching its spike proteins to the ACE-2 receptor molecules present in human respiratory epithelial cells [48]. Once the virus reaches a person's respiratory tract, an RBD epitope located in the S1 domain protruding out of a SARS-CoV-2 virion membrane binds to an ACE-2 receptor on a respiratory or nasal mucosal epithelial cell facilitating the entry of the SARS-CoV-2 virion into the cell $[45,49]$. Specifically, it is the receptor binding motif (RBM), a specific part of the RBD S1 domain, that attaches to the ACE-2 receptors on human cells. This occurs more frequently on the nasal mucosal cells, where the virus has easy and frequent access. More specifically, the RBM residue, located within the 227 amino acids long RBD region (p319 - p546 residue), binds to ACE-2 receptor proteins present on the respiratory mucosal epithelial cells [50]. Soon, the entire S1 domain of the spike protein is cleaved by the furin and TMPRSS2 enzymes hanging off from the mucosal cells making the S2 subunit free from the S1 subunit. Soon after, with the assistance of mucosal cell proteases, the S2 domain undergoes proteolysis, losing some amino acids (Arg815-Ser833) and exposing some other amino acids (Ser861-Phe833) and becomes competent for fusion with the mucosal cell membrane of the host [51,52]. Following that, the S2 subunit attaches to the SARS-CoV-2 virion membrane with free C-terminal amino acids (Ser861-Phe833) and leads to insertion of SARS-CoV-2 virion into the cell [51-53].

\section{SARS-CoV-2 replication mechanism inside the host:}

Once inside the human cell, the SARS-CoV-2 viral genome is released into the cytoplasm of the mucosal cell. The SARS-CoV-2 positive mRNA genome is copied into a negative mRNA molecule which translates the viral proteins: the N, M, E, and S proteins. Side by side, a positive SARS-CoV-2 mRNA is also transcribed from the negative SARS-CoV-2 mRNA. While the $N$ proteins bind to the positive SARSCoV-2 mRNA for providing and holding its structure, the $E, M$ and S proteins attach to the ER membrane of the host cell. This segment is soon transferred to the Golgi apparatus to pack the SARS-CoV-2 mRNA positive strand inside a phospholipid membrane carrying the $E, M$, and $S$ proteins, forming a vesicle. This in turn moves towards the mucosal cell membrane to be released outside as an active SARS-CoV-2 virion 
particle [54]. The infection time has been estimated to be $10-15$ minutes and the replication time for generating progeny virions takes 7-8 hours, releasing 6-7 $\times 10^{2}$ pfu per burst [40].

\section{SARS-CoV-2 vaccine development:}

All types of viruses mutate and evolve as they replicate; their prolonged presence in an uncontrolled environment favors development of new variants, including some with potentially deleterious results. Their ability to generate de novo diversity in a short period of time and the rate of spontaneous mutation varies among viruses: mutation rates in RNA viruses are higher than in DNA viruses and single stranded viruses have higher mutation rates than double-strand viruses [55].

Hence, only vaccinating a smaller segment of a population against SARS-CoV-2 may favor the generation of new variants with new infectivity. In that scenario, even the vaccinated individuals would face risks from arrivals of new variants. This would be enhanced further, since active SARS-CoV-2 may get transmitted back and forth between humans to pet animals, as already observed in Italy [56]. This may only be brought under control by administering a safe and effective vaccine as soon as possible to a significantly large part of the population. Successes of such efforts will reduce development of new variants and thus help the global human population attain herd immunity [57].

As cases of COVID-19 were growing globally, the efforts of worldwide biotechnologists, scientists, experts, pharmaceuticals, and investors were brought together to develop effective vaccines against SARS-CoV-2 as quickly as possible. Hundreds of biotechnological and pharmaceutical institutions, individuals, and companies across the globe sought to develop effective vaccines against SARS-CoV- 2 . More than 50 such vaccine candidates were put into human trials in 2020 and a total of 250 vaccine candidates were in the process before any were selected [58]. The safety and effectiveness of a vaccine is measured by its long-term antigenicity and immunogenicity for its therapeutic application as a vaccine.

The SARS-CoV-2 virus mutates at a rate four times slower than the influenza virus, and the new variants have a minimal effect on the antigenicity of the virus $[59,60]$. Although the coronaviruses mutate at a slower rate, some of the new variants of SARS-CoV-2, such as D 614 G, mutate outside the RBD residue and have higher rates of infectivity by boosting viral replication in lung and respiratory tract tissues $[61,62]$.

Since the SARS-CoV-2 S-protein molecules located on the virus's outer surface are critical for its binding with ACE-2 receptors on human cells, the S-protein should be the most effective antigen in 
developing antibodies against SARS-CoV-2 causing COVID-19. The currently administered COVID-19 vaccines are antigenic; either SARS-CoV-2 S-protein mRNA or SARS-CoV-2 S-protein cDNA incorporated into an adenoviral vector DNA [63-65].

These vaccines express the entire viral S-protein once they enter the cells of the vaccine recipient. The role of the vaccine protein is to trigger immune cells and produce immunity against future viral infections. The mRNA antigenic vaccine for COVID-19 contains a genetically modified mRNA molecule enclosed inside a lipid nanoparticle (LNP). This encodes the SARS-CoV-2 S-protein. The recipient of this vaccine produces the S-protein antigen, which is received by the T cells, and is followed up with antibody production by the B cells. The antibody has the potential to block SARS-CoV-2 infection by attaching to the RBD epitopes of S-protein [66].

\section{Potential risks associated with mRNA and adenovirus mediated DNA vaccines:}

\subsection{Risks associated with mRNA vaccines:}

Breakage and repair of double stranded DNA molecules are common inside human cells. Repair with high fidelity is essential for genetic stability and good health [67]. In some cases, mRNA serves as a DNA damage code and promotes homologous recombination [68]. As a result, the entrance of any foreign mRNA inside human cells poses a risk to the stability of the cellular genome of the recipient. Also, there are several instances of evidence for live, attenuated viral RNA vaccines to recombine with similar or other viral genomes in circulation in the recipient's plasma, affecting the effectiveness of RNA vaccines $[69,70]$.

DNA:RNA hybrids constitute a well-known source of recombinogenic DNA damage [71]. Spontaneous mitotic recombination is a well-known process, and it is also enhanced by transcription [72]. The frequency of transcription increases double strand breaks and/or single stranded DNA gaps which become susceptible to RNA-DNA recombination from bacteria to human. This takes place on the replication forks during transcription by provoking stalling and/or breakage. Furthermore, transcription - replication creates recombinogenic DNA breaks by forming co-transcriptional R-loops as a way where RNA influences genome dynamics. The above phenomenon poses a question on the potential interference and thus risks associated with SARS-CoV-2 S-protein mRNA vaccines on the cells and thus health of the vaccine recipients.

Zhang [73] published evidence of SARS-CoV-2 chimeric transcripts in primary cells of patients as well as SARS-CoV-2 infected cells in culture. There is also reported evidence of fusion and retro- 
integration of the SARS-CoV-2 genome into human DNA and its subsequent expression. There is further evidence of RNAs of SARS-CoV-2 being reverse-transcribed in cells of infected human patients either by their endogenous LINE-1 or HIV-1 reverse transcriptase, as LINE-1 expression is induced in patients following SARS-CoV-2 infection. It is also reported that cells in culture exposed to cytokine induces LINE1 expression. Furthermore, human patients infected by SARS-CoV-2 were found to continue to produce the viral RNA even after recovery, suggesting the existence of a different mechanism of viral RNA replication in human. These instances of evidence support the existence of a molecular mechanism for SARS-CoV-2 retro-integration into the human genome and thus putting a challenge to the use of SARSCoV-2 mRNA or cDNA as vaccines.

Another group of scientists reported their observation of increased retrotransposon expression and upregulation of 10-11 translocation enzymes in lung-derived cells collected from SARS-CoV-2 infected human patients [74]. They hypothesized that coronavirus invades human cells, interacts with retrotransposons, and may cause harm through retrotransposon dysregulation. These authors support our view that SARS-CoV-2 S-protein mRNA vaccines, as well as cDNA vaccines, have the potential to enter the human cell genome in a way that might harm the recipient.

\subsection{Risks associated with adenoviral and adeno-associated viral vector mediated vaccines:}

Although adenoviruses and adeno-associated viruses (AAV) have been used as a vehicle for gene transfer and human gene therapy for some time, they also pose risks and dangers to the recipients [75, 76]. Unfortunately, these vectors also integrate external genes into the recipient's genome. Although rare, it was demonstrated that genes carried by AAV vectors integrate in a site-specific manner into the $q$ arm of human Chromosome 19 which may also express when the virus enters the lytic cycle, induced by a helper virus, as recorded in AAV virus therapy [77].

In an in vivo experiment using mice, the median frequency of chromosomal integrations of adenoviral vector DNA into mice chromosomes were found to be $6.72 \times 10^{-5}$ as heterologous recombination and $3.88 \times 10^{-7}$ as homologous recombination [78]. Furthermore, recipients who were previously exposed to the adenoviral vector (which is very common) might have pre-existing immunities for the vector, and hence the efficacy of the COVID-19 cDNA vaccine using the adenoviral vector may not be as effective. This indicates the potential risks for using SARS-CoV-2 CDNA vaccines carried by the adenovirus vector. 


\section{Why did we choose RBD protein vaccine?}

The RBD is a small segment of the S-protein of the SARS-CoV-2 virion. The RBD is critical to bind the virus to the ACE-2 receptors on human mucosal cells. The binding leads to infection, followed by the disease COVID-19. Hence, using RBD as an antigen for producing a vaccine to protect humans from SARS-CoV-2 infections will be highly specific, and thus highly effective.

According to Huang [42], the S-protein located on the SARS-CoV-2 virus envelope is composed of 1273 amino acids (aa). The S-protein consists of a 13 aa long signal peptide (1-13 residues), followed by a 672 aa long S1 domain (14-685 residues), and is completed with a 588 aa long S2 domain (6861273 residues). The S1 domain contains a 292 aa long N-terminal domain (14-305 residues) and a 223 aa long RBD (319-541 residues). The SARS-CoV-2 encapsulating membrane holds many trimeric Sproteins, each containing the RBD proteins as a trimer that binds to the ACE-2 receptors present in human cells [79]. Furthermore, Yang [80] also demonstrated that the S1 domain of the SARS-CoV-2 spike protein directly binds to ACE-2 receptors expressed by the undifferentiated human alveolar cells (A549) facilitating the SARS-CoV-2 entry into the cells. It was also reported that a SARS-CoV-2 receptor-blocking human antibody, HA001, attaches to amino acids A475 and F486 residues in the RBD of the SARS-CoV-2 spike protein [81]. In this process, a 71 amino acid long segment of the RBD, the RBM, tightly binds to the ACE-2 receptor [82]. Furthermore, the RBD contains nine cysteine residues making four pairs and one free. The three pairs are Cys336-Cys361, Cys379-Cys432, and Cys391-Cys525 residues that form the core RBD $\beta$ sheet, and the remaining pair, Cys480-Cys488 residue, binds to the $\mathrm{N}$-terminal peptidase domain of ACE-2 [83]. All the above experimental evidence supports that the RBD protein will be a highly effective antigen for a SARS-CoV-2 vaccine.

After the binding of RBD to ACE-2, two enzymes from human mucosal cells, furin and TMPRSS2, cleave the S1 domain from the S2 domain $[49,84]$. Then, the S2 domain protein (with SARS-CoV-2 virus attached) fuses with the human mucosal cell membrane allowing the entry of the virus into human cells followed by the release of SARS-CoV-2 mRNA into the cell cytoplasm.

The mRNA selected for an antigenic vaccine encodes the entire spike protein that is 1273 aa long $[63,85]$. Hence, it produces both the S1 and S2 domains of the S-protein as an antigen, although the S2 domain of SARS-CoV has been reported to produce no immunity against SARS-CoV viral infection in mice [86]. Furthermore, after the removal of the S1 domain, the S2 domain of SARS-CoV-2 binds to human mucosal cells making the pathway for the SARS-CoV-2 virus to enter the cell. 
Now the question remains to be answered: will the free S2 domain protein from the antigen produced by the mRNA vaccines allow entrance of any free SARS-CoV-2 virus into human mucosal cells and cause an infection and thus the disease? With minor differences, the two types of mRNA antigenic vaccines currently being administered to the public also contain the entire region of the mutant Sprotein $[63,87]$ gene. Hence, they will also produce both the S1 and S2 domain proteins. Once the S1 domain is separated by furin and TMPRSS2 from the S2 domain, what is the potential for the S2 domain to transfer the free-floating SARS-CoV-2 virus into the human mucosal cells, causing infection and the disease? Furthermore, using the S2 domain independently as an antigen in BALB/C mice failed to produce neutralizing antibodies against infection by SARS-CoV [86]. Hence, the free S2 domain released from the S1 domain produced by the mRNA vaccines plays no role to generate immunity against SARSCoV-2 infections.

\section{Conclusion}

The RBD protein of SARS-CoV-2 is an excellent choice for developing vaccines to prevent COVID-19. The RBD itself is an antigen, and hence it will be direct and quick in stimulating the recipients' systems to produce antibodies against SARS-CoV-2 virions quickly. Furthermore, since it is not composed of any nucleotides or nucleic acids, it has no potential for homologous recombination in the recipient's genome. The vaccines composed of antigenic mRNA have a short life in the recipients' cells, hence it is possible that some recipients of mRNA vaccines may develop limited immunity against SARS-CoV-2. Furthermore, both antigenic mRNA and cDNA have the potential for homologous recombination through reverse transcriptase when present and active in the recipients' system.

On the other hand, protein vaccines, like the SARS-CoV-2 RBD, can generate a strong immune response and can be used by almost everyone who needs them, including people with weakened immune systems and long-term health problems [87]. Furthermore, the RBD protein vaccines cannot cause the COVID-19 disease. However, booster shots may be necessary to have a full protection against the ongoing SARS-CoV-2 infections $[88,89]$.

Acknowledgements: We would like to thank Arthee E. Jahangir, Ph.D. and Arnab Z. Jahangir for their editorial support. 


\section{References}

1. Chan, J.F-W., To, K. K-W., Tse, H., Jin, D-Y., Yuen, K-Y. (2013). Interspecies transmission and emergence of novel viruses: lessons from bats and birds Jasper. Trends in Microbiology. 21(10), 544-555.

2. Tyrell, D., \& Bynoe, M. (1966). Cultivation of viruses from a high proportion of patients with colds. The Lancet, 287(7428), 76-77. https://doi.org/10.1016/s0140-6736(66)92364-6.

3. Kapikian, A. Z. (1975) The coronaviruses. Dev Biol Stand. 28:42-64.

4. Kahn, J. S., \& McIntosh, K. (2005). History and recent advances in coronavirus discovery. Pediatric Infectious Disease Journal, 24(11), S223-S227. https://doi.org/10.1097/01.inf.0000188166.17324.60.

5. Edridge, A.W.D., Kaczorowska, J., Hoste, A.C.R., Bakker, M., Klein, M., Loens, K., Jebbink, M.F., Matser, A., Kinsella, C. M., Rueda, P., leven, M., Goossens, H., Prins, M., Sastre, P., Deijs, M., Lia van der Hoek. (2020). Seasonal coronavirus protective immunity is short-lasting. Nat Med 26, 1691-1693. https://doi.org/10.1038/ s41591-020-1083-1.

6. Xu, R-H, He, J-F, Evans MR, Peng G-W, Field HE, Yu D-W, Lee, C-K, Luo, H-M, Lin W-S, Lin, P., Li, L-H, Liang, W-J, Lin, J-Y, \& Schnur, A. (2004). Epidemiologic clues to SARS origin in China. Emerg Infect Dis. 10(6), 10301037.

7. Peiris, J. S., Lai, S. T., Poon, L. L., Guan, Y., Yam, L. Y., Lim, W., Nicholls, J., Yee, W. K., Yan, W. W., Cheung, M. T., Cheng, V. C., Chan, K. H., Tsang, D. N., Yung, R. W., Ng, T. K., Yuen, K. Y., \& SARS study group (2003). Coronavirus as a possible cause of severe acute respiratory syndrome. Lancet (London, England), 361(9366), 1319-1325. https://doi.org/10.1016/s0140-6736(03)13077-2

8. Shi, Z., \& Hu, Z. (2008). A review of studies on animal reservoirs of the SARS coronavirus. Virus research, 133(1), 74-87. https://doi.org/10.1016/j.virusres.2007.03.012.

9. Li, X., Zai, J., Zhao, Q., Li, Y., Foley, B., Chaillon, A. (2020b). Evolutionary history, potential intermediate animal host, and cross-species analyses of SARS-CoV-2. Journal of Medical Virology 92(6), 602-611.

10. Wang, H., Li, X., Li, T., Zhang, S., Wang, L., Wu, X., and Liu, J. (2020). The genetic sequence, origin, and diagnosis of SARS-CoV-2. European journal of clinical microbiology \& infectious diseases: official publication of the European Society of Clinical Microbiology, 39(9),1629-1635. https://doi.org/10.1007/s10096-020-03899-4

11. Mackay, \& Arden, K. E. (2015). MERS coronavirus: Diagnostics, epidemiology and transmission. Virology Journal, 12(1), 222-243. https://doi.org/10.1186/s12985-015-0439-5.

12. Zumla, A., Hui, D. S., \& Perlman, S. (2015). Middle East respiratory syndrome. The Lancet, 386(9997), 9951007. https://doi.org/10.1016/s0140-6736(15)60454-8.

13. Mohd, H.A., Al-Tawfiq, J.A. \& Memish, Z.A. Middle East Respiratory Syndrome Coronavirus (MERS-CoV) origin and animal reservoir. Virol J 13, 87 (2016). https://doi.org/10.1186/s12985-016-0544-0.

14. Hemida, M.G., Ali M., Alhammadi, M., Alnaeem, A. (2020). The Middle East respiratory syndrome coronavirus in the breath of some infected dromedary camels (Camelus dromedarius). Epidemiol Infect. 2020 Oct 14;148:e247. doi: 10.1017/S0950268820002459. PMID: 33050973; PMCID: PMC7588717.

15. Coleman, C.M., Sisk, J.M., Mingo, R.M., Nelson, E. A., White, J.M., Frieman, M.B. (2016). Abelson Kinase Inhibitors Are Potent Inhibitors of Severe Acute Respiratory Syndrome Coronavirus and Middle East Respiratory Syndrome Coronavirus Fusion. J Virol. 90(19), 8924-8933.

16. Killerby, M. E., Biggs, H. M., Midgley, C. M., Gerber, S. I., \& Watson, J. T. (2020). Middle East Respiratory Syndrome Coronavirus Transmission. Emerging Infectious Diseases, 26(2), 191-198. https://dx.doi.org/10.3201/eid2602.190697.

17. Lu, H., Stratton, C. W., \& Tang, Y. W. (2020). The Wuhan SARS-CoV-2-What's next for China. Journal of medical virology, 92(6), 546-547. https://doi.org/10.1002/imv.25738.

18. Li, X., Cui, W., \& Zhang, F. (2020a). Who Was the First Doctor to Report the COVID-19 Outbreak in Wuhan, China? Journal of nuclear medicine: official publication, Society of Nuclear Medicine, 61(6), 782-783. https://doi.org/10.2967/inumed.120.247262

19. Chen, B., Tian, EK., He, B., Tian, L., Han, R., Wang, S., Xiang, Q., Zhang, S., Arnaout, TE., Cheng W. (2020a). Overview of lethal human coronaviruses. Sig Transduct Target Ther 5, 89-105.

20. Yuan, S., Jiang, S., \& Li, Z. (2020b). Analysis of possible intermediate hosts of the new coronavirus SARS-Cov2. Frontiers in Veterinary Science, 7. https://doi.org/10.3389/fvets.2020.00379. 
21. Zhu, Z., Lian, X., Su, X., Wu, W., Marraro, G. A., \& Zeng, Y. (2020b). From SARS and MERS to COVID-19: A summary and comparison of severe acute respiratory infections caused by three highly pathogenic human coronaviruses. Respiratory Research, 21(1). https://doi.org/10.1186/s12931-020-01479-w.

22. Naqvi, A., Fatima, K., Mohammad, T., Fatima, U., Singh, I. K., Singh, A., Atif, S. M., Hariprasad, G., Hasan, G. M., \& Hassan, M. I. (2020). Insights into SARS-CoV-2 genome, structure, evolution, pathogenesis and therapies: Structural genomics approach. Biochimica et biophysica acta. Molecular basis of disease, 1866(10), 165878. https://doi.org/10.1016/j.bbadis.2020.165878

23. WHO (2020a). Naming-the-coronavirus-disease-(covid-2019)-and-the-virus-that-causes-it. https://www.who.int/emergencies/diseases/novel-coronavirus-2019/technical-guidance/

24. Pal, M., Berhanu, G., Desalegn, C., \& Kandi, V. (2020). Severe Acute Respiratory Syndrome Coronavirus-2 (SARSCoV-2): An Update. Cureus, 12(3), e7423. https://doi.org/10.7759/cureus.7423.

25. JHU (Johns Hopkins University), (2021). COVID-19 pandemic: Tracking the global coronavirus outbreak. National public health agencies and UN population data figures last updated: March 17, 2021, 8:30PM EST.

26. Dennis, M. J. (2020). The impact of COVID -19 on the world economy and higher education. Enrollment Management Report, 24(9), 3-3. https://doi.org/10.1002/emt.30720.

27. Gassman-Pines, A., and Gennetian, L. A. (2020). COVID-19 Job and Income Loss Jeopardize Child Well-Being: Income Support Policies Can Help. Society for Research in Child Development. Child Evidence Brief. No.9.

28. Mahajan, C., Kapoor, I., \& Prabhakar, H. (2020). Psychological effects of COVID-19 on children of health care workers. Anesthesia \& Analgesia, 131(3), e169-e170. https://doi.org/10.1213/ane.0000000000005034.

29. Oh, D. L., Jerman, P., Silvério Marques, S., Koita, K., Purewal Boparai, S. K., Burke Harris, N., \& Bucci, M. (2018). Systematic review of pediatric health outcomes associated with childhood adversity. BMC Pediatrics, 18(1). https://doi.org/10.1186/s12887-018-1037-7.

30. Jackwood, M. W. (2006). The relationship of severe acute respiratory syndrome coronavirus with avian and other coronaviruses. Avian Diseases, 50(3), 315-320. https://doi.org/10.1637/7612-042006r.1

31. Woo, P.C.Y., Lau, S.K.P, Huang, Y., \& Yuen K-Y. (2009). Coronavirus Diversity, Phylogeny and Interspecies Jumping. Exp Biol Med 234:1117-1127. https://journals.sagepub.com/ doi/pdf/10.3181/0903-MR-94.

32. Lau, S., Luk, H., Wong, A., Li, K., Zhu, L., He, Z., Fung, J., Chan, T., Fung, K., \& Woo, P. (2020). Possible Bat Origin of Severe Acute Respiratory Syndrome Coronavirus 2. Emerging infectious diseases, 26(7): 1542-1547. https://doi.org/10.3201/eid2607.200092.

33. Hu, B., Guo, H., Zhou, P., \& Shi, Z. (2020). Characteristics of SARS-Cov-2 and COVID-19. Nature Reviews Microbiology, 19(3), 141-154. https://doi.org/10.1038/s41579-020-00459-7.

34. Ji, W., Wang, W., Zhao, X., Zai, J., Li, X. (2020). Cross-species transmission of the newly identified coronavirus 2019-nCoV. J Med Virol. 92(4):433-440. doi: 10.1002/jmv.25682. PMID: 31967321; PMCID: PMC7138088.

35. Flores-Alanis, A., Sandner-Miranda, L., Delgado, G., and Cravioto, A. (2020) Morales-Espinosa R. The receptor binding domain of SARS-CoV-2 spike protein is the result of an ancestral recombination between the batCoV RaTG13 and the pangolin-CoV MP789. BMC Res Notes. 2020 Aug 27;13(1):398. doi: 10.1186/s13104020-05242-8. PMID: 32854762; PMCID: PMC7450963.

36. Zhang, T., Wu, Q. and Zhang, Z. (2020c). Probable Pangolin Origin of SARS-CoV-2 Associated with the COVID-19 Outbreak. Current Biology. 30:1346-1351.

37. Jaimes, J. A., André, N. M., Chappie, J. S., Millet, J. K., \& Whittaker, G. R. (2020). Phylogenetic Analysis and Structural Modeling of SARS-CoV-2 Spike Protein Reveals an Evolutionary Distinct and Proteolytically Sensitive Activation Loop. Journal of molecular biology, 432(10), 3309-3325.

https://doi.org/10.1016/i.jmb.2020.04.009.

38. Qing, E., \& Gallagher, T. (2020). SARS coronavirus Redux. Trends in Immunology, 41(4), 271273. https://doi.org/10.1016/j.it.2020.02.007.

39. Zhu, N., Zhang, D., Wang, W., Li, X., Yang, B., Song, J., Zhao, X., Huang, B., Shi, W., Lu, R., Niu, P., Zhan, F., Ma, X., Wang, D., Xu, W., Wu, G., Gao, G. F., Tan, W., \& China Novel Coronavirus Investigating and Research Team (2020a). A Novel Coronavirus from Patients with Pneumonia in China, 2019. The New England journal of medicine, 382(8), 727-733. https://doi.org/10.1056/NEJMoa2001017.

40. Bar-On, Y. M., Flamholz, A., Phillips, R., \& Milo, R. (2020). SARS-CoV-2 (COVID-19) by the numbers. elife, 9 , e57309. https://doi.org/10.7554/eLife.57309. 
41. Chen, L., Liu, W., Zhang, Q., Xu, K., Ye, G., Wu, W., Sun, Z., Liu, F., Wu, K., Zhong, B., Mei, Y., Zhang, W., Chen, Y., Li, Y., Shi, M., Lan, K., \& Liu, Y. (2020b). RNA based mNGS approach identifies a novel human coronavirus from two individual pneumonia cases in 2019 Wuhan outbreak. Emerging microbes \& infections, 9(1), 313-319. https://doi.org/10.1080/22221751.2020.1725399.

42. Huang, Y., Yang, C., Xu, X., Xu, W., \& Liu, S. (2020). Structural and functional properties of SARS-Cov-2 spike protein: Potential antivirus drug development for COVID-19. Acta Pharmacologica Sinica, 41(9), 11411149. https://doi.org/10.1038/s41401-020-0485-4.

43. Mercatelli, D., \& Giorgi, F. M (2020). Geographic and Genomic Distribution of SARS-CoV-2 Mutations. Microbiol., 22 July 2020 https://doi.org/10.3389/fmicb.2020.01800.

44. Mishra, A., Pandey, A.K., Gupta, P., Pradhan, P., Dhamija, S., Gomes, J., Kundu, B.,Vivekanandan, P., \& Menon, P.B. (2020). Mutation landscape of SARS-CoV-2 reveals five mutually exclusive clusters of leading and trailing single nucleotide substitutions. BioxRxiv. doi:https://doi.org/10.1101/2020.05.07.082768.

45. Schoeman, D. \& Fielding, B.C. (2019). Coronavirus envelope protein: current knowledge. Virology Journal 16: 69. https://doi.org/10.1186/s12985-019-1182-0.

46. Astuti, I., and Ysrafil. (2020). Severe Acute Respiratory Syndrome Coronavirus 2 (SARS-CoV-2): An overview of viral structure and host response. Diabetes \& metabolic syndrome, 14(4), 407-412. https://doi.org/10.1016/ j.dsx. 2020.04.020.

47. Ma, Y., Wu, L., Shaw, N., Gao, Y., Wang, J., Sun, Y., Lou, Z., Yan, L., Zhang, R., \& Rao, Z. (2015). Structural basis and functional analysis of the SARS coronavirus nsp14-nsp10 complex. Proceedings of the National Academy of Sciences of the United States of America, 112(30): 9436-9441. https://doi.org/10.1073/pnas.1508686112.

48. Perrotta, F., Matera, M. G., Cazzola, M., \& Bianco, A. (2020). Severe respiratory SARS-CoV-2 infection: Does ACE-2 receptor matter? Respiratory medicine, 168, 105996. https://doi.org/10.1016/j.rmed.2020.105996.

49. Li, F. F. (2016). Structure, Function, and Evolution of Coronavirus Spike Proteins. Annu Rev Virol. 3(1): $237-261$. https://doi.org/10.1146/annurev-virology-110615-042301.

50. Letko, M., Marzi, A., \& Munster, V. (2020). Functional assessment of cell entry and receptor usage for SARSCov-2 and other lineage B betacoronaviruses. Nature Microbiology, 5(4), 562-

569. https://doi.org/10.1038/s41564-020-0688-y.

51. Shyr, Z. A., Gorshkov, K., Chen, C. Z., \& Zheng, W. (2020). Drug discovery strategies for SARS-Cov-2. Journal of Pharmacology and Experimental Therapeutics, 375(1), 127-138. https://doi.org/10.1124/jpet.120.000123.

52. Fuentes-Prior, P. (2021). Priming of SARS-Cov-2 S protein by several membrane-bound serine proteinases could explain enhanced viral infectivity and systemic COVID-19 infection. Journal of Biological Chemistry, 296, 100135. https://doi.org/10.1074/jbc.rev120.015980.

53. Belouzard, S., Millet, J.K., Licitra, B.N., Whittaker, G.R. (2012). Mechanisms of coronavirus cell entry mediated by the viral spike protein. Viruses. 4(6): 1011-33. doi:10.3390/v4061011.

54. V'kovski, P., Kratzel, A., Steiner, S., Stalder, H., and Thiel, V. (2020). Coronavirus biology and replication: Implications for SARS-CoV-2. Nature Reviews Microbiology, 19(3), 155-

170. https://doi.org/10.1038/s41579-020-00468-6.

55. Sanjuán, R., \& Domingo-Calap, P (2016). Mechanisms of viral mutation. Cellular and Molecular Life Sciences, 73(23), 4433-4448. https://doi.org/10.1007/s00018-016-2299-6.

56. Patterson, E., Elia, G., Grassi, A., Giordano, A., Desario, C., Medardo, M., Smith, S., Anderson, E., Prince, T., Patterson, G., Lorusso, E., Lucente, M., Lanave, G., Lauzi, S., Bonfanti, U., Stranieri, A., Martella, V., Basano, F. S., Barrs, V., ... Decaro, N. (2020). Evidence of exposure to SARS-CoV-2 in cats and dogs from households in Italy. Nat Commun 11, 6231 (2020). https://doi.org/10.1038/s41467-020-20097-0.

57. Mallory, M. L., Lindesmith, L. C., \& Baric, R. S. (2018). Vaccination-induced herd immunity: Successes and challenges. The Journal of allergy and clinical immunology, 142(1), 64-66. https://doi.org/10.1016/j.jaci.2018.05.007.

58. Agrawal, G., Conway, M., Heller, J., Sabow, A., Tolub, G. (2020). On pins and needles: Will COVID-19 vaccines 'save the world'? McKinsey \& Company, Pharmaceutical \& Medical Products Practice. Pages 1-16. https://www.mckinsey.com/industries/pharmaceuticals-and-medical-products/our-insights/on-pins-andneedles-will-covid-19-vaccines-save-the-world.

59. Moshiri, N. (2020). Coronavirus seems to mutate much slower than seasonal flu. Live Science, 
60. Zhang, L., Jackson, C. B., Mou, H., Ojha, A., Rangarajan, E. S., Izard, T., Farzan, M., Choe, H. (2020a). The D614G mutation in the SARS-CoV-2 spike protein reduces S1 shedding and increases infectivity. bioRxiv, June 12, 2020, biorxiv.com

61. Plante, J.A., Liu, Y., Liu, J. Xia, H., Johnson, B.A., Lokugamage, K.G., Zhang, X., Muruato, A.E., Zou, J., FontesGarfias, C.R., Mirchandani, D., Scharton, D., Bilello, J.P., Ku, Z., An, Z., Kalveram, B., Freiberg, A. N., Menachery, V.D., Xie, X., Plante, K.S., Weaver, S. C., Shi, P-Y. (2020). Spike mutation D614G alters SARSCoV-2 fitness. Nature. https://doi.org/10.1038/s41586-020-2895-3.

62. Rausch, J. W., Capoferri, A. A., Katusiime, M. G., Patro, S. C., \& Kearney, M. F. (2020). Low genetic diversity may be an Achilles heel of SARS-Cov-2. Proceedings of the National Academy of Sciences, 117(40), 2461424616. https://doi.org/10.1073/pnas.2017726117.

63. Shimabukuro, T. T., Kim, S. Y., Myers, T. R., Moro, P. L., Oduyebo, T., Panagiotakopoulos, L., Marquez, P. L., Olson, C. K., Liu, R., Chang, K. T., Ellington, S. R., Burkel, V. K., Smoots, A. N., Green, C. J., Licata, C., Zhang, B. C., Alimchandani, M., Mba-Jonas, A., Martin, S. W., ... Meaney-Delman, D. M. (2021). Preliminary findings of mRNA COVID-19 vaccine safety in pregnant persons. New England Journal of Medicine. https://doi.org/10.1056/nejmoa2104983.

64. Livingston, E. H., Malani, P. N., \& Creech, C. B. (2021). The Johnson \& Johnson vaccine for COVID19. JAMA, 325(15), 1575. https://doi.org/10.1001/jama.2021.2927.

65. Vogel, G., \& Kupferschmidt, K. (2021). Side effect worry grows for AstraZeneca vaccine. Science, 372(6537), 1415. https://doi.org/10.1126/science.372.6537.14.

66. Smith, T. R. F., Patel, A., Ramos, S., Elwood, D., Zhu, X., Yan, J., Gary, E. N., Walker, S. N., Schultheis, K., Purwar, M., Xu, Z., Walters, J., Bhojnagarwala, P., Yang, M., Chokkalingam, N., Pezzoli, P., Parzych, E., Reuschel , E. L., Doan, A., Tursi, N., Vasquez, M., Choi, J., Tello-Ruiz, E., Maricic, I., Bah, M. A., Wu, Y., Amante, D., Park, D.H., Dia, Y., Ali, A. R., Zaidi, F.I., Generotti, A., Kim, K.Y., Herring, T. A., Reeder, S., Andrade, V. M., Buttigieg, K., Zhao, G., Wu J-M., Li, D., Bao, L., Liu, J., Deng, W., Qin, Ch., Brown, A. S., Khoshnejad, M., Wang, N., Chu, J., Wrapp, D., McLellan, J. S., Muthumani, K., Wang, B., Carroll, M. W., Kim, J. J., Boyer, J., Kulp, D. W., Humeau, L. M. P. F., Weiner, D. B., \& Broderick, K. E. (2020). Immunogenicity of a DNA vaccine candidate for COVID-19. Nature Communications, 11(1). https://doi.org/10.1038/s41467-020-16505-0.

67. Shen, L., Wang, Q., Liu, R., Chen, Z., Zhang, X., Zhou, P., \& Wang, Z. (2018). LncRNA Inc-RI regulates homologous recombination repair of DNA double-strand breaks by stabilizing RAD51 mRNA as a competitive endogenous RNA. Nucleic acids research, 46(2), 717-729. https://doi.org/10.1093/nar/gkx1224.

68. Chen, H., Yang, H., Zhu, X. Yadav, T., Ouyang, J., Truesdell, S.S., Tan, J., Wang, Y., Duan, M., Wei, L., Zou, L., Levine, A.S., Vasudevan S., and Lan, L. (2020c). $\mathrm{m}^{5} \mathrm{C}$ modification of mRNA serves a DNA damage code to promote homologous recombination. Nat Commun 11, 2834.

https://doi.org/10.1038/s41467-020-16722-7.

69. Han, G., Li, S., \& Liu, X. (2008). Caution about Newcastle disease virus-based live attenuated vaccine. Journal of Virology, 82(13), 6782-6782. https://doi.org/10.1128/jvi.00370-08.

70. Li, B., Fang, L., Xu, Z., Liu, S., Gao, J., Jiang, Y., Chen, H., \& Xiao, S. (2009). Recombination in vaccine and circulating strains of porcine reproductive and respiratory syndrome viruses. Emerging infectious diseases, 15(12), 2032-2035. https://doi.org/10.3201/eid1512.090390.

71. Lafuente-Barquero, J., Martin-Alonso, M. S., Gómez-González, B., \& Aguilera, A. (2020). Harmful DNA:RNA hybrids are formed in cis and in a rad51-independent Manner. https://doi.org/10.1101/2020.04.20.047134.

72. Aguilera, A., \& Gaillard, H. (2014). Transcription and recombination: when RNA meets DNA. Cold Spring Harbor perspectives in biology, 6(8), a016543. https://doi.org/10.1101/cshperspect.a016543.

73. Zhang, L., Richards, A., Khalil, A., Wogram, E., Ma, H., Young, R.A., and Jaenisch, R. (2020). SARS-CoV-2 RNA reverse-transcribed and integrated into the human genome. bioRxiv 2020.12.12.422516; doi: https://doi.org/10.1101/2020.12.12.422516

74. Yin, Y., Liu, X. Z., He, X., \& Zhou, L. Q. (2021). Exogenous Coronavirus Interacts With Endogenous Retrotransposon in Human Cells. Frontiers in cellular and infection microbiology, 11, 609160. https://doi.org/10.3389/fcimb.2021.609160.

75. Song, L., Samulski, R. J., \& Hirsch, M. L. (2020). Adeno-associated virus vector mobilization, risk versus reality. Human Gene Therapy, 31(19-20), 1054-1067. https://doi.org/10.1089/hum.2020.118. 
76. Bulcha, J. T., Wang, Y., Ma, H., Tai, P. W., \& Gao, G. (2021). Viral vector platforms within the gene therapy landscape. Signal Transduction and Targeted Therapy, 6(1). https://doi.org/10.1038/s41392-021-00487-6.

77. Vannucci, L., Lai, M., Chiuppesi, F., Ceccherini-Nelli, L., \& Pistello, M. (2013). Viral vectors: a look back and ahead on gene transfer technology. New Microbiol. 2013 Jan;36(1):1-22. Epub 2013 Jan 1. PMID: 23435812.

78. Stephen, S. L., Montini, E., Sivanandam, V. G., Al-Dhalimy, M., Kestler, H. A., Finegold, M., Grompe, M., \& Kochanek, S. (2010). Chromosomal integration of Adenoviral vector DNA in vivo. Journal of Virology, 84(19), 9987-9994. https://doi.org/10.1128/jvi.00751-10.

79. Yuan, M., Wu, NC., Zhu, X., Lee, C-C D., So, T.T.Y., Lv, H., Chris K. P. Mok, C.K.P., \& Wilson, I.A. (2020a). A highly conserved cryptic epitope in the receptor-binding domains of SARS-CoV-2 and SARSCoV. Science 10.1126/science. Abb 7269 (2020).

80. Yang, J., Petitjean, S.J.L., Koehler, M. Zhang, Q. Dumitru, A. C. Chen, W. Derclaye, S. Vincent, S. P. Soumillion P. \& Alsteens, D. (2020a). Molecular interaction and inhibition of SARS-CoV-2 binding to the ACE-2 receptor. Nat Commun 11, 4541 (2020). https://doi.org/10.1038/s41467-020-18319-6.

81. Yi, C., Sun, X., Ye, J., Ding, L., Liu, M., Yang, Z., Lu, X., Zhang, Y., Ma, L., Gu, W., Qu, A., Xu, J., Shi, Z., Ling, Z., \& Sun, B. (2020). Key residues of the receptor binding motif in the spike protein of SARS-Cov-2 that interact with ACE2 and neutralizing antibodies. Cellular \& Molecular Immunology, 17(6), 621630. https://doi.org/10.1038/s41423-020-0458-z.

82. Khalaj-Hedayati, A. (2020). Protective Immunity against SARS Subunit Vaccine Candidates Based on Spike Protein: Lessons for Coronavirus Vaccine Development. Journal of immunology research, 2020, 7201752. https://doi.org/10.1155/2020/7201752.

83. Lan, J., Ge, J., Yu, J., Shan, S., Zhou, H., Fan, S., Zhang, Q., Shi, X., Wang, Q., Zhang, L., \& Wang, X. (2020). Structure of the SARS-Cov-2 spike receptor-binding domain bound to the ACE2 receptor. Nature, 581(7807), 215-220. https://doi.org/10.1038/s41586-020-2180-5

84. Bestle, D., Heindl, M. R., Limburg, H., Van, T. V., Pilgram, O., Moulton, H., Stein, D. A., Hardes, K., Eickmann, M., Dolnik, O., Rohde, C., Becker, S., Klenk, H., Garten, W., Steinmetzer, T., \& Böttcher-Friebertshäuser, E. (2020). TMPRSS2 and furin are both essential for proteolytic activation and spread of SARS-Cov-2 in human airway epithelial cells and provide promising drug targets. https://doi.org/10.1101/2020.04.15.042085.

85. CDC (2021). https://www.cdc.gov/coronavirus/2019-ncov/vaccines/different-vaccines/Moderna. html\#print). Updated Mar. 4, 2021.

86. Guo, Y., Sun, S., Wang, K., Zhang, S., Zhu, W., \& Chen, Z. (2005). Elicitation of immunity in mice after immunization with the S2 subunit of the severe acute respiratory syndrome coronavirus. DNA and Cell Biology, 24(8), 510-515. https://doi.org/10.1089/dna.2005.24.510.

87. https://www.hhs.gov/immunization/basics/types/index.html

88. https://www.proteogenix.science/scientific-corner/peptide-synthesis/conventional-vs-peptide-vaccines/

89. Nelde, A., Rammensee, H., \& Walz, J.S. (2021). The peptide vaccine of the future. Molecular \& Cellular Proteomics, 20, 100022. https://doi.org/10.1074/mcp.r120.002309 